\title{
Single-incision versus standard multi- incision laparoscopic colectomy in patients with malignant or benign colonic disease: a systematic review, meta-analysis and assessment of the evidence
}

\author{
Anne Catharina Brockhaus ${ }^{1,2^{*}}$, Stefan Sauerland ${ }^{3}$ and Stefan Saad ${ }^{4}$
}

\begin{abstract}
Background: Single-incision laparoscopic colectomy (SILC) requires only one umbilical port site and (depending on technique) a specimen extraction site.

The aim of this study was the assessment of the available evidence for the comparison of SILC to conventional multi-port laparoscopic colectomy (MLC) in adult patients, in whom elective colectomy is indicated because of malignant or benign disease. First, previous meta-analyses on this topic were assessed. Secondly, a systematic review and meta-analysis of randomised controlled trials, was performed.

Methods: Electronic literature searches (CENTRAL, MEDLINE and EMBASE; up to March 2016) were performed. Additionally, we searched clinical trials registries and abstracts from surgical society meetings. For meta-analysis, risk ratios (RR) or mean differences (MD) with $95 \%$ confidence intervals were calculated and pooled. The quality of previous meta-analyses was evaluated against established criteria (AMSTAR) and their reported results were investigated for consistency.

Results: We identified 6 previous meta-analyses of mostly low methodological quality (AMSTAR total score: $2-5$ out of 11 items). To fill the evidence gaps, all these meta-analyses had included non-randomised studies, but usually without assessing their risk of bias. In our systematic review and meta-analysis of randomised controlled trials exclusively, we included two randomised controlled trials with a total of 82 colorectal cancer patients. There was insufficient evidence to clarify whether SILC leads to less local complications (RR $=0.52,95 \% \mathrm{Cl} 0.14-1.94$ ) or lower mortality (1 death per treatment group). Length of hospital stay was significantly shorter in the SILC group ( $M D=-1.20$ days, $95 \% \mathrm{Cl}-1.95$ to -0.44 ). One of the two studies found postoperative pain intensity to be lower at the first day. We also identified 7 ongoing trials with a total sample size of over 1000 patients.

Conclusion: The currently available study results are too sparse to detect (or rule out) relevant differences between SILC and MLC. The quality of the current evidence is low, and the additional analysis of non-randomised data attempts, but does not solve this problem. SILC should still be considered as an experimental procedure, since the evidence of well-designed randomised controlled trials is too sparse to allow any recommendation.
\end{abstract}

Keywords: Single port, Mini-invasive, Laparoscopy, Surgery, Colon

\footnotetext{
* Correspondence: catharina.brockhaus@iqwig.de

'Department of Medical Biometry, Institute for Quality and Efficiency in Health Care (IQWiG), Cologne, Germany

${ }^{2}$ Institute for Health Economics and Clinical Epidemiology, University of

Cologne, Cologne, Germany

Full list of author information is available at the end of the article
}

\section{Biomed Central}

(c) 2016 The Author(s). Open Access This article is distributed under the terms of the Creative Commons Attribution 4.0 International License (http://creativecommons.org/licenses/by/4.0/), which permits unrestricted use, distribution, and reproduction in any medium, provided you give appropriate credit to the original author(s) and the source, provide a link to the Creative Commons license, and indicate if changes were made. The Creative Commons Public Domain Dedication waiver (http://creativecommons.org/publicdomain/zero/1.0/) applies to the data made available in this article, unless otherwise stated. 


\section{Background}

During conventional multi-port laparoscopic colonic resection (MLC), the camera and surgical instruments are inserted through $4-5$ trocars. The resected colon part is extracted by an additional minilaparotomy (i.e. low Pfannenstiel or midline incision). Laparoscopic colonic surgery increasingly became the new standard for colorectal resection $[1,2]$. There is evidence that incisional hernias are less frequent using the totallaparoscopic approach instead of open abdominal surgery [3]. For caesarean section, wound length was found as a risk factor for surgical-site complications [4].

Therefore, newer approaches and advances of the minimal invasive surgery aim to minimise the total length of incisions even further, which in turn may reduce the morbidity of the abdominal wall, such as wound pain, wound infection and hernia formation. This implies the expectation of a faster recovery in the early postoperative phase. One way to achieve this aim is to minimise the number of incisions used. Singleincision laparoscopic colectomy (SILC) uses only one umbilical port site $[5,6]$. However, the likely limitations of SILC include an additional learning curve and advanced laparoscopic skill requirements [7], because triangulation is missing, when all instruments are oriented intraabdominally in the same direction $[8,9]$.

There are several meta-analyses published [10-15] comparing SILC to MLC, none of which included randomised controlled trials exclusively, but predominantly observational studies such as case-matched studies. Most of these reviews noted substantial heterogeneity in some of their outcomes $[10,11,13]$, which might reflect the differences in study design, surgical technique, patient selection, postoperative care or even the incomplete learning curve among the different studies. The potential bias of the results due to the low quality of the included studies was also addressed by several reviews [10-12]. It is important to assess the efficacy and safety of SILC by preparing this systematic review based on only RCTs. Including only RCTs minimises the heterogeneity and potential bias mentioned above that might be introduced into the analysis by the inclusion of observational studies.

The aim of this work is the assessment of the available evidence. This includes an investigation of the methodological quality and results of previously published meta-analyses comparing SILC to MLC in adult patients. Furthermore and as previously specified in the protocol to this systematic review [16], we compared SILC to MLC in adult patients, in whom elective colectomy is indicated because of malignant or benign disease, by performing a systematic review and meta-analysis of randomised controlled trials.

\section{Methods}

Previously published meta-analyses on this topic (i.e. SILC vs. MLC) were systematically identified from the same literature searches as described below. Metaanalyses were eligible, if they examined SILC in the treatment of malignant or benign diseases of colon or rectum. The methodological quality of these metaanalyses was assessed by using AMSTAR ('A Measurement Tool to Assess Systematic Reviews'), which contains 11 single items and give a maximum score of 11 points [17]. The appraisal of meta-analyses was independently done by two reviewers.

We conducted this systematic review according to a pre-specified protocol [16]. The protocol describes the surgical procedures studied, the eligible patient groups, as well as the pre-specified methods (i.e. criteria for considering studies for this review, search strategy, data collection and analysis). Thus, unless stated otherwise, the present systematic review was performed according to the protocol [16].

The search was conducted from 2008 to March 2016. Electronic literature searches were performed in the databases CENTRAL, MEDLINE and EMBASE. For the search in two clinical trial registries, the following terms were used: 'single-incision laparoscopic colectomy', 'single-port laparoscopic colectomy', 'single AND colectomy', 'single AND incision AND colon', 'single AND incision AND colectomy', 'single AND port AND colon', 'single AND port AND colectomy', 'transumbilical AND colectomy', 'transumbilical AND colon,' 'notes AND colectomy', 'notes AND colon'. In addition, a manual search of several potentially relevant systematic reviews and metaanalyses on this topic $[10-15,18]$ was carried out to identify additional trials.

Eligible studies were selected independently by two authors according to the previously specified criteria (i.e. RCT, SILC and MLC as intervention, adult patients, in whom elective colectomy was indicated because of either malignant or benign disease). Primary outcomes were previously defined as local complications (intraand postoperative events) and mortality. Secondary outcomes were defined as conversion rate to laparoscopic, hand-assisted laparoscopic or open surgery, estimated blood loss, operative time, number of patients with R0 resection, tumour-free resections or both, number of lymph nodes harvested, postoperative pain intensity, general complications, resumption of bowel function, length of hospital stay, quality of life or fatigue, cosmetic results and disease-free survival.

We contacted authors of potentially eligible studies to obtain any missing information. The study by Poon et al. [19] presented their results as median, but they kindly provided mean and standard deviations for their reported continuous outcomes upon request. Therefore, 
no imputation of missing data was relevant. The risk of bias assessment was performed using the criteria described in the Cochrane Handbook for Systematic Reviews of Interventions [20].

We intended to explore reasons for heterogeneity (Chi2 test with significance being set at $P$ value $<0.05$ ) in the studies using subgroup and sensitivity analysis, but this was not possible due to the low number of studies. This is also the reason, why the assessment of potential publication bias using a funnel plot would not have been meaningful. In cases of substantial statistical heterogeneity we did not pool the results. Analysis was conducted using Review Manager Version 5.3 [21].

\section{Results}

\section{Assessment of previous meta-analyses}

A total of 8 systematic reviews comparing SILC to MLC were found $[10-15,18,22]$. Two reviews [18, 22] also included case series and case reports and were therefore excluded from detailed assessment here.

Thus, we investigated the methodological quality of 6 systematic reviews, all of which also included metaanalyses [10-15]. According to the AMSTAR instrument $[17$, a systematic review is well done, when all the Items on the checklist have been fulfilled. As summarized in Table 1, all of the systematic reviews complied with only two to five of the 11 items. Major issues were a missing a priori published protocol, presentation of the search strategy or additional searches such as trial registries or conference proceedings and a missing quality assessment of the included studies. All systematic reviews checked whether heterogeneity existed for the included studies, but nearly all the systematic reviews pooled the studies regardless of the presence or absence of statistical heterogeneity. Furthermore, there were several discrepancies among the systematic reviews with regard to the inclusion of primary studies (Table 2). Therefore, the results and conclusions of these reviews may be affected by substantial methodological bias stemming from either the primary studies or the systematic review itself.

\section{Systematic review and meta-analysis of randomised con- trolled trials}

We retrieved 686 records (531 different publications after duplicates removed) through database searching and 10 additional records through other sources (society meetings and study register), of which 529 records clearly did not meet the inclusion criteria and were therefore excluded. Four records were only available as conference abstracts [60-64]. We contacted the authors, who either did not respond or confirmed that their study is still ongoing [63, 64]. One study was only available as study protocol [65] and the other five records were only listed as study registration without any full-text available.

Two full texts randomised trials $[19,23]$ were retrieved, evaluated in detail and included in the present review. We did not identify any additional study from screening the reference lists of included studies, potentially-relevant systematic reviews on the same topic, online trial registries or congress proceedings. The result of this search was illustrated in the flow diagram (Fig. 1).

\section{Study characteristics}

We identified two randomised controlled trials [19, 23] were included in this systematic review. None of the included studies investigated benign diseases. Thus the following results are derived only for malignant diseases. In the study by Poon et al. [19], specimen extraction was done through the umbilicus, whereas Huscher et al. [23] also used a colpotomy in female patients. While the

Table 1 Assessment of methodological quality of systematic reviews by using the AMSTAR instrument

\begin{tabular}{|c|c|c|c|c|c|c|c|c|c|c|c|c|}
\hline Systematic review & 11 & 12 & 13 & 14 & 15 & 16 & 17 & 18 & 19 & 110 & 111 & AMSTAR Total score \\
\hline Podda 2016 [15] & $n$ & $?$ & y & y & $n$ & y & $n$ & $n$ & $\mathrm{n}$ & y & y & 5 \\
\hline Markar 2014 [14] & $\mathrm{n}$ & $?$ & $?$ & y & $n$ & y & $n$ & $\mathrm{n}$ & $n$ & y & y & 4 \\
\hline Maggiori 2012 [10] & $n$ & $?$ & $n$ & $y$ & $n$ & y & y & y & $n$ & $n$ & y & 5 \\
\hline Zhou 2012 [11] & $\mathrm{n}$ & $?$ & $?$ & $n$ & y & y & y & $n$ & $n$ & y & y & 5 \\
\hline Li 2012 [12] & $\mathrm{n}$ & $?$ & $\mathrm{n}$ & $\mathrm{n}$ & $\mathrm{n}$ & y & $\mathrm{n}$ & $n$ & y & y & $\mathrm{n}$ & 3 \\
\hline Yang 2012 [13] & $\mathrm{n}$ & $?$ & $?$ & $\mathrm{n}$ & $\mathrm{n}$ & y & $\mathrm{n}$ & $\mathrm{n}$ & $\mathrm{n}$ & y & $n$ & 2 \\
\hline
\end{tabular}

$\mathrm{y}$ : yes, the criteria are met; $\mathrm{n}$ : no, the criteria are not met; ?: can't answer

11: Was an 'a priori' design provided?

12: Was there duplicate study selection and data extraction?

13: Was a comprehensive literature search performed?

14: Was the status of publication (i.e. grey literature) used as an inclusion criterion?

15: Was a list of studies (included and excluded) provided?

16: Were the characteristics of the included studies provided?

17: Was the scientific quality of the included studies assessed and documented?

18: Was the scientific quality of the included studies used appropriately in formulating conclusions?

19: Were the methods used to combine the findings of studies appropriate?

110: Was the likelihood of publication bias assessed?

111: Was the conflict of interest included? 
Table 2 Characteristics of assessed systematic reviews

\begin{tabular}{|c|c|c|c|}
\hline Author (Year) & Types of resections included & Included studies & Conclusion on SILC \\
\hline Podda et al. [15] & $\begin{array}{l}\text { Right-sided, left-sided or total colectomy } \\
\text { (including ileocecal resection) }\end{array}$ & $\begin{array}{l}30 \text { studies: } 2 \text { RCTs [19, 23], } 28 \text { observational studies } \\
\text { [24-51] }\end{array}$ & "safe and feasible" \\
\hline Markar et al. [14] & Right-sided, left-sided or total colectomy & $\begin{array}{l}34 \text { studies: } 2 \text { RCTs }[19,23], 32 \text { observational studies } \\
{[24-48,52-58]}\end{array}$ & $\begin{array}{l}\text { "similar short-term clinical } \\
\text { and oncological outcomes" }\end{array}$ \\
\hline Maggiori et al. [10] & Right-sided, left-sided or total colectomy & $\begin{array}{l}15 \text { studies: } 0 \text { RCTs, } 15 \text { observational studies } \\
{[24-26,30-32,36-39,41,43,46,47,52]}\end{array}$ & "feasible and safe" \\
\hline Zhou et al. [11] & $\begin{array}{l}\text { Right-sided, left-sided or total colectomy } \\
\text { (including ileocecal resection) }\end{array}$ & $\begin{array}{l}14 \text { studies: } 1 \text { RCT [23], } 13 \text { observational studies } \\
{[24,26,30,32,34,37,38,41,43,46,52,55,56]}\end{array}$ & $\begin{array}{l}\text { "safe, feasible, and } \\
\text { oncologically efficient" }\end{array}$ \\
\hline Li et al. [12] & unclear & $\begin{array}{l}11 \text { studies: } 1 \text { RCT [23], } 10 \text { observational studies } \\
{[24-26,30,31,37,41,46,52,55]}\end{array}$ & "short-term results similar" \\
\hline Yang et al. [13] & Right-sided or left-sided colectomy & $\begin{array}{l}15 \text { studies: } 1 \text { RCT [23], } 14 \text { observational studies } \\
{[24-26,30-32,34,37,41,43,44,46,47,59]}\end{array}$ & "similar safety and efficacy" \\
\hline
\end{tabular}

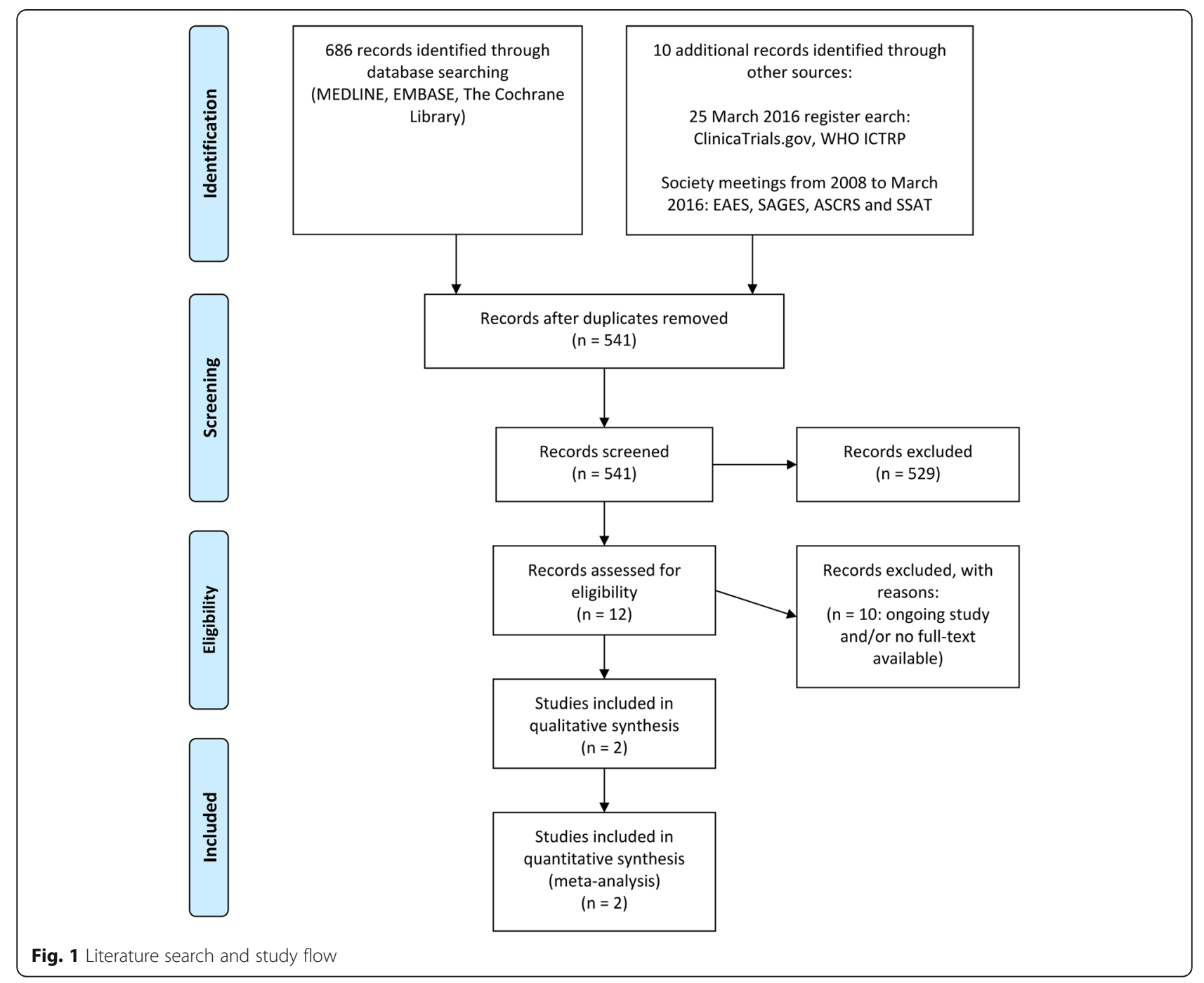


Table 3 Baseline characteristics of studies included in the meta-analysis

\begin{tabular}{|c|c|c|c|c|c|c|c|c|}
\hline Author, year (country) & $\begin{array}{l}\text { No. of } \\
\text { patients }\end{array}$ & Age in years & Gender (M/F) & $\mathrm{BMI}$ in $\mathrm{kg} / \mathrm{m}^{2}$ & $\operatorname{ASA}(1,2,3)$ & $\begin{array}{l}\text { Type of colectomy } \\
\text { (left/right) }\end{array}$ & $\begin{array}{l}\text { Cancer sta } \\
(1,2,3)\end{array}$ & \\
\hline \multirow[t]{4}{*}{ Huscher et al. [26], 2012 (Italy) } & 32 & $70 \pm 11$ & $15 / 17$ & not reported & $8(25 \%)$ & SILC: $8 / 8$ & SILC: & MLC: \\
\hline & (16 vs. 16) & $($ mean \pm SEM $)$ & & & $15(47 \%)$ & MLC: 10/6 & $5(31 \%)$ & $4(25 \%)$ \\
\hline & & & & & $9(28 \%)$ & & 7 (44 \%), & $9(56 \%)$ \\
\hline & & & & & & & $4(25 \%)$ & $3(19 \%)$ \\
\hline \multirow[t]{4}{*}{ Poon et al. [16], 2012 (China) } & 50 & $\begin{array}{l}\text { SILC: } 67 \\
(37-83)^{a}\end{array}$ & SILC: 14 / 11 & $\begin{array}{l}\text { SILC: } 23.2 \\
(16.9-28.8)^{a}\end{array}$ & $6(12 \%)$ & SILC: $17^{b} / 8$ & SILC: & MLC: \\
\hline & (25 vs. 25) & $\begin{array}{l}\text { MLC: } 67 \\
(57-81)^{a}\end{array}$ & MLC: $18 / 7$ & $\begin{array}{l}\text { MLC: } 23.6 \\
(16.5-28.2)^{\mathrm{a}}\end{array}$ & 37 (74 \%), & MLC: $16^{\mathrm{b}} / 9$ & $8(32 \%)$ & $5(20 \%)$ \\
\hline & & & & & $7(14 \%)$ & & $7(28 \%)$ & $4(16 \%)$ \\
\hline & & & & & & & $6(24 \%)$ & $12(48 \%)$ \\
\hline
\end{tabular}

$M$ Male, $F$ Female, BMI body mass index, ASA American Society of Anaesthesiologists, SILC Single-incision laparoscopic colectomy, $M L C$ multi-incision laparoscopic colectomy ${ }^{a}$ Data are given as median with range ${ }^{b_{\text {including }}}$ anterior resection and sigmoidectomy

patients in the study by Poon et al. [19] received an enhanced recovery program, this was not mentioned in the studies by Huscher et al. [23]. The characteristics of the included studies are summarised in Table 3.

We assessed the overall risk of bias of the study by Huscher et al. [23] as high, due to an unclear random sequence generation (exact method of sequence generation not specified), missing blinding of the participants, personnel and outcome assessors, as well as a missing study registration, definition of a primary outcome variable or pre-specified sample size (high risk due to possibly selective reporting).

We assessed the overall risk of bias of the study by Poon et al. [19] as low, because all of the assessed risks of bias were low, except for the documented surgical experience, which was not reported in the publication. The authors kindly informed us that all the conventional laparoscopic colectomies were operated by a team of four surgeons (experience of more than 50 MLC cases), of whom two surgeons (experience of more than 10 SILC) performed all the single incision laparoscopic. We assessed the risk of bias due to a possibly not completed learning curve as unclear.

The results of the risk of bias assessment are summarised in Fig. 2.

\section{Primary outcomes}

There was no statistically significant difference observed in the pooled complication rates between the two treatment groups ( $R R=0.52(95 \% \mathrm{CI} 0.14-1.94)$, Fig. 3). In the study by Huscher et al. [23] one (6,3\%) major complication (anastomotic leakage, intraoperative bleeding) was reported for each intervention group and 1 minor complications (wound infection) in the SILC group and 2 minor complications (wound infections) in the MLC group. None of the reported complications by Poon et al. [19] were major complications (SILC group: one wound infection, MLC group: two wound infections and one ileus).

The mortality at longest available follow-up was not statistically significant between the two treatment groups in the study by Huscher et al. [23] (one (6,3\%) in each treatment group). The thirty-day mortality in this study was nil for both treatment groups, however, one patient in the SILC group died after 20 months of metastatic disease and one patient in the MLC group died after 12 months of a peritoneal carcinosis. There was no mortality in both treatment groups in the study by Poon et al. [19].

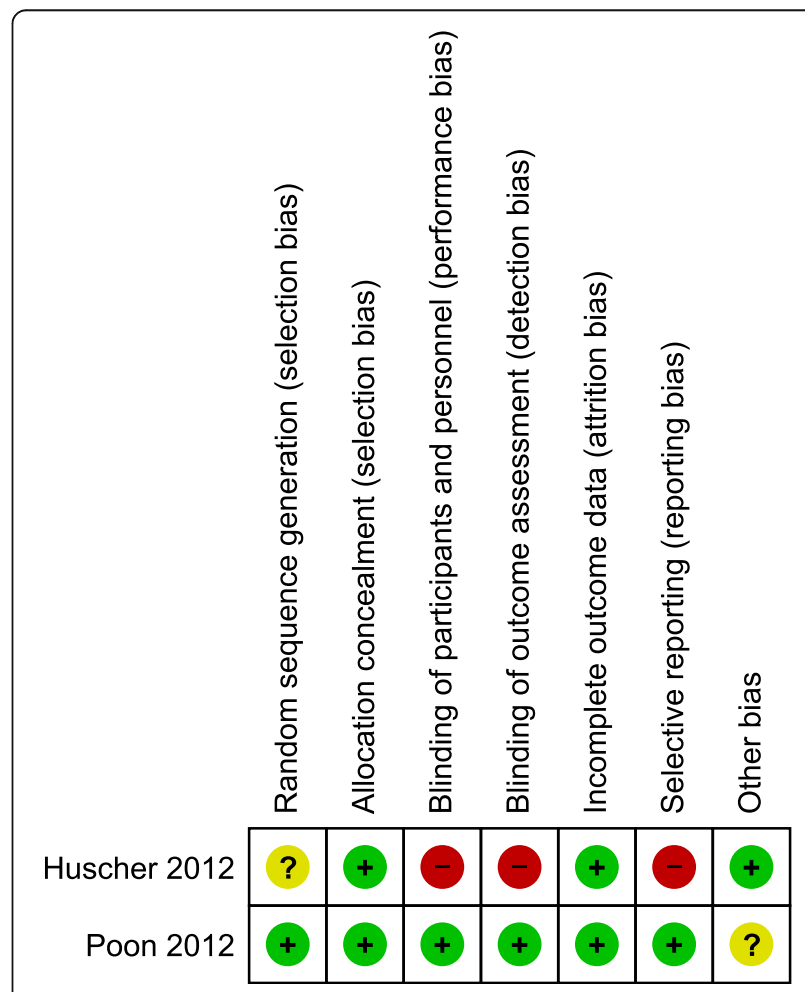

Fig. 2 Risk of bias summary: review authors' judgements about each risk of bias item for each included study 


\begin{tabular}{|c|c|c|c|c|c|c|c|c|c|c|}
\hline Study or Subgroup & \multicolumn{2}{|c|}{ SILC } & \multicolumn{2}{|l|}{ MLC } & Weight & $\begin{array}{c}\text { Risk Ratio } \\
\text { M-H, Random, } 95 \% \mathrm{Cl} \\
\end{array}$ & \multicolumn{4}{|c|}{$\begin{array}{c}\text { Risk Ratio } \\
\text { M-H, Random, } 95 \% \mathrm{CI}\end{array}$} \\
\hline Huscher 2012 & 2 & 16 & 3 & 16 & $63.9 \%$ & $0.67[0.13,3.47]$ & & 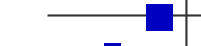 & & \\
\hline Poon 2012 & 1 & 25 & 3 & 25 & $36.1 \%$ & $0.33[0.04,2.99]$ & & & & \\
\hline Total $(95 \% \mathrm{Cl})$ & & 41 & & 41 & $100.0 \%$ & $0.52[0.14,1.94]$ & & & & \\
\hline Total events & 3 & & 6 & & & & & & & \\
\hline \multicolumn{7}{|c|}{ Heterogeneity: $\mathrm{Tau}^{2}=0.00 ; \mathrm{Chi}^{2}=0.25, \mathrm{df}=1(\mathrm{P}=0.62) ; \mathrm{I}^{2}=0 \%$} & 0.02 & $\begin{array}{l}0.1 \\
\text { Favours SILC }\end{array}$ & $\begin{array}{l}10 \\
\text { Favours MLC }\end{array}$ & 50 \\
\hline
\end{tabular}

\section{Secondary outcomes}

Due to the small number of included studies and events, we considered pooling data for only three (operative time, length of hospital stay and number of lymph nodes) of the 12 regarded secondary outcomes. For the other outcomes, the uncertainty about any estimated effect measure would be very high and its presentation might be misleading.

While there was no statistically significant difference between SILC and MLC observed for the operative time $(\mathrm{MD}=+15 \min (95 \% \mathrm{CI}-3-33)$, Fig. 4$)$, the length of hospital stay was one day shorter in the SILC group $(\mathrm{MD}=-1$ day (95 \% CI -1.95 to -0.44$)$, Fig. 5). There was substantial heterogeneity determined for the number of lymph nodes $\left(P\right.$ value $=0.03 ; \mathrm{I}^{2}=80 \%$, Fig. 6$)$. Thus a pooled estimate for this outcome was not meaningful and no conclusions can be drawn from these data.

No significant differences were reported for the outcomes tumour-free margins $[19,23]$, conversion rate $[19,23]$, general complication $[19,23]$, estimated blood loss [19], bowel function or disease-free survival [23].

The reported postoperative pain intensity by Poon et al. [19] was presented without any adjustment for multiplicity. But even with a simple Bonferroni correction $[66,67]$ for all the compared pain scores, the day one result for the NRS pain score at rest remained statistically significantly different between the two treatment groups (SILC: nil (range 0-5), MLC: three (range $0-6), P$ value $=0.002$ ) .

None of the included studies examined cosmetic results, quality of life, or fatigue.

\section{Ongoing and unpublished trials}

We identified 7 ongoing randomised trials comparing SILC and MLC through our additional search of two clinical trials registries (Table 4). We contacted the authors of trials with anticipated study completion date through 2017 to investigate the actual status of the trials and when we could expect their results to be available, but we either did not get any response or the author confirmed that they were still recruiting. Especially the last trial, due to its size of included participants, is very likely to have an important impact on our confidence in the estimate of effects and might even change the estimates.

\section{Discussion}

We assessed 6 previous meta-analyses, which all tried to overcome the current sparseness of high-quality data by including observational studies such as case-matched studies. We assessed the methodological quality of these reviews and found it to be rather low. Therefore, the results and conclusions of these reviews may be affected by substantial methodological bias. Furthermore, we noticed that their reported results were inconsistent. While three reviews $[10,11,15]$ reported that they could not find any difference concerning the conversion rate, one review [12] reported a higher conversion rate in the SILC group and another review reported a lower conversion rate in the SILC group [14]. We also noticed that several eligible studies were not included by several of these meta-analyses, although these primary studies were published at the time of literature search.

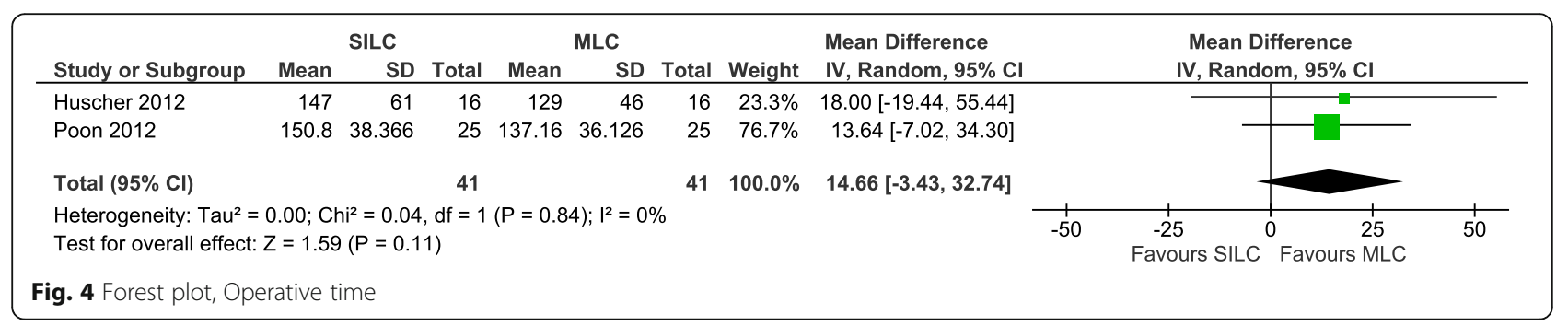




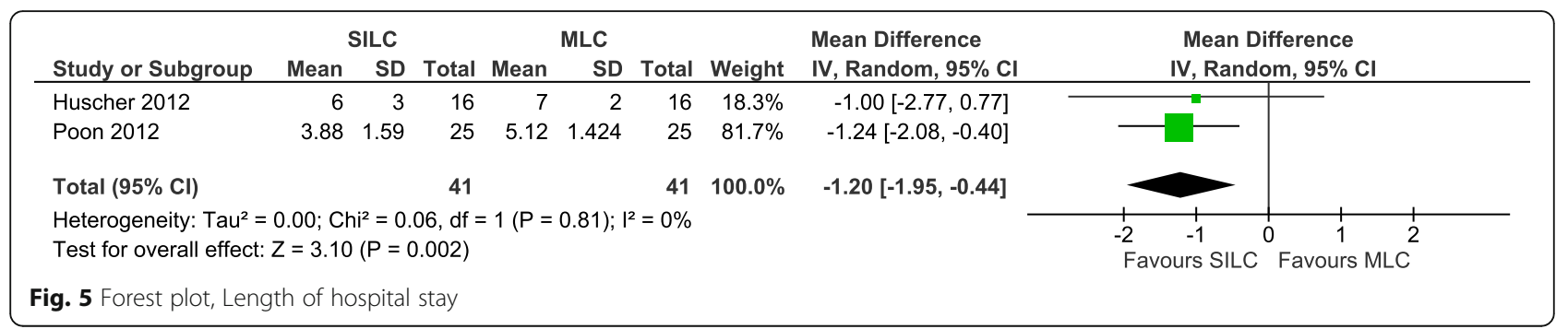

In the our systematic review and meta-analysis we identified two randomised controlled trials $[19,23]$, including 82 participants with malignant diseases, 41 in each of the two treatment. There were no patients with benign diseases included in this review. Based on these trials we found insufficient evidence to clarify whether single-incision laparoscopic colectomy (SILC) leads to less local complications (including both intraoperative and postoperative events) or lower mortality. Due to the small number of included studies, lack of event occurrence, as well as substantial heterogeneity in one outcome (number of lymph nodes harvested), metaanalyses were conducted only for two (operative time and length of hospital stay) of the 12 regarded secondary outcomes. Besides a significantly shorter hospital stay of one day, there was no statistically significant difference between SILC and MLC observed.

The total length of scar was not reported in either of the included studies. However, according to the description of the operation procedures, the reduction of total incision length in the SILC group is only a few centimetres. After adjustment for multiplicity, the reported postoperative pain intensity by Poon et al. [19] was statistically significantly reduced in the SILC group at the first day after the operation. The pain intensity of SILC was 1.64 points lower on average compared to the MLC with a $95 \%$ confidence interval of $0.67-2.61$. Since the confidence interval is relatively wide, it is not clear whether this difference is clinically important [68]. Since none of the studies reported cosmetic results, quality of life, or fatigue, and the reported reduction of pain intensity in the SILC group may be clinically unimportant, there is no evidence to investigate any potential dependency between post-operative comfort and total length of scars. Further randomised controlled trials are necessary to replicate reported results and to resolve inconsistencies between the studies.

The quality of the evidence was low, due to the sparse data and because the results from one of the two included studies were of a high risk of bias. Thus, the main limitation of this systematic review is the limited number of patients included in the meta-analysis for primary outcomes and very limited available results on secondary endpoints. However, this is not a limitation of our work but due to a lack of evidence and therefore not remediable.

The results of randomised and non-randomised studies sometimes differ [69] and non-randomised studies produce, on average, effect estimates that indicate more extreme benefits of the effects of health care than randomised trials [70], which is why it is not surprising that our review, including only RCTs, differs from these other reviews in some of the outcomes. Since these reviews predominantly present non-significant or heterogeneous results, our results are mostly in agreement with at least one of the reviews results. Thus, the inclusion of observational data does not lead to more reliable clinical recommendations, but instead leads to heterogeneity of results and increases risk of bias, due to the very low quality of the included studies. Clearly, more data are not necessarily better data. Therefore, our review presents the most reliable evidence currently available, by means of randomised controlled trials.

Although the available data are very sparse, so that there is a possibility that the lack of findings are due to a lack of evidence of effect and not due to a lack of effect itself, studies evaluating single incision laparoscopic surgery in different application areas showed similar results. A recent patient- and assessor-blinded randomised multi-centre trial [71], as well as a review including 659

\begin{tabular}{|c|c|c|c|c|c|c|c|c|c|c|c|c|}
\hline \multirow[b]{2}{*}{ Study or Subgroup } & \multicolumn{3}{|c|}{ SILC } & \multicolumn{3}{|c|}{ MLC } & & \multirow{2}{*}{$\begin{array}{l}\text { Mean Difference } \\
\text { IV, Random, } 95 \% \mathrm{Cl}\end{array}$} & \multirow{2}{*}{\multicolumn{3}{|c|}{$\begin{array}{c}\text { Mean Difference } \\
\text { IV, Random, } 95 \% \mathrm{CI}\end{array}$}} & \\
\hline & Mean & SD & Total & Mean & SD & Total & Weight & & & & & \\
\hline Huscher 2012 & 18 & 6 & 16 & 16 & 5 & 16 & & $2.00[-1.83,5.83]$ & & $\rightarrow$ & 1 & \\
\hline \multirow[t]{2}{*}{ Poon 2012} & 15.6 & 6.157 & 25 & 20.22 & 9.247 & 25 & & $-4.62[-8.97,-0.27]$ & & -1 & & \\
\hline & & & & & & & & & -10 & $\begin{array}{c}-5 \\
\text { Favours MLC }\end{array}$ & $\begin{array}{c}5 \\
\text { Favours SILC }\end{array}$ & 10 \\
\hline
\end{tabular}


Table 4 Ongoing randomised controlled trials

\begin{tabular}{|c|c|c|c|c|}
\hline Registration number & Author & Country & Estimated completion date & $\begin{array}{l}\text { Estimated enrollment } \\
n\end{array}$ \\
\hline NCT01626963 & David W Borowski & UK & 2016 & 50 \\
\hline NCT01203969 & Suk Hwan Lee & Korea & 2012 & 60 \\
\hline ISRCTN55622645 & Weida Day & China & 2012 & 100 \\
\hline NCT01959087 & Yves Panis & France & 2017 & 128 \\
\hline NCT02117557 & Guoxin Li & China & 2022 & 198 \\
\hline JPRN-UMIN000007220 & Mitsuyoshi Ota & Japan & 2020 & 200 \\
\hline NCT01480128 & Hyung-Jin Kim & Korea & 2017 & 388 \\
\hline
\end{tabular}

patients from nine RCTs investigating single incision versus multi-incision laparoscopic cholecystectomy [72], could not show any benefit of single-incision laparoscopic cholecystectomy in postoperative pain, operating time, hospital stay and complication rate. The only significant benefit single-incision laparoscopic cholecystectomy showed in those studies was a better cosmetic result. Thus, one should consider the possibility that small advantages of SILC might be clinically irrelevant. Also, the available data enclosed in our review did not include a sufficient follow-up period to assess any longterm benefit or harm, so that a potentially negative effect of SILC cannot be excluded.

Although some surgeons will rate the present metaanalysis with only two included studies as not very valuable, it is important to describe how little data on SILC exist so far. Neither our review, including randomised controlled studies, nor the reviews, which also included observational studies, could confirm the safety. The lack of high-quality studies precludes a confirmation of safety, both in the short-term and in the oncological long-term. Nevertheless, surgeons increasingly practice SILC, which can be seen by the increasing number of published articles on this topic. The number of comparative studies published in the last four years has almost tripled [10, 11, 13-15], not counting the case reports and series published during this time. Hence, the main purpose of our systematic review is to remind the surgical community, currently deciding whether or not to use this new method that safety and effectiveness of SILC are yet to be confirmed. Also, this review acts as a warning sign that SILC should only be performed in a research setting. It is inevitable to wait for the results of further RCTs to be published.

\section{Conclusion}

The currently available study results are too sparse to detect (or rule out) relevant differences between SILC and MLC. The quality of the current evidence is low, and the additional analysis of non-randomised data attempts, but does not solve this problem. For colorectal cancer patients, it is essential to assess oncologic outcomes (e.g. disease-free survival) in the long-term. For some complications (e.g. incisional hernia), a longer follow-up time is also necessary. SILC should still be considered as an experimental procedure, since the evidence of well-designed randomised controlled trials is too sparse to allow any recommendation.

\section{Abbreviations}

AMSTAR: A Measurement Tool to Assess Systematic Reviews; ASA: American Society of Anesthesiologists; BMI: Body mass index; MD: Mean differences; MLC: Multi-port laparoscopic colectomy; RR: Risk ratio; SILC: Single-incision laparoscopic colectomy; TSC: Trial search coordinator

\section{Acknowledgments}

We thank the trial search coordinator (TSC) of CCCG for developing the Search strategy. We are very grateful to Elke Hausner for supporting us by screening the titles and abstracts of our electronic search from 2008 to 2015. We thank Dr. Poon, Dr. Mingoli, Dr. Zapolskiy and Dr. Panis for providing additional information on their trials.

\section{Funding}

This investigation and manuscript preparation received no external funding.

\section{Availability of data and materials}

The data supporting the conclusions of this article is included within the article.

\section{Authors' contributions}

ACB coordinated the review, drafted the review, screened the resulting references of the electronic search and online trial registries, hand searched abstracts from society meetings and checked the reference lists of retrieved studies and several potentially-relevant systematic reviews and meta-analysis on this topic, retrieved papers, screened the retrieved papers against eligibility criteria, extracted the data, appraised the quality of the included studies as well as the methodological quality of previous systematic reviews, wrote to authors of papers for additional information, entered data into RevMan, analysed the data, and interpreted the results. StS conceived the idea for this review, drafted the protocol and review, extracted the data, appraised the quality of the included studies as well as the methodological quality of previous systematic reviews, wrote to authors of papers for additional information, and interpreted the results. SSa commented on all surgical content. All authors read and approved the final manuscript.

Competing interest

The authors declare that they have no competing interests.

\section{Consent for publication}

Not applicable.

Ethics approval and consent to participate

Not applicable.

\section{Author details}

${ }^{1}$ Department of Medical Biometry, Institute for Quality and Efficiency in Health Care (IQWiG), Cologne, Germany. ${ }^{2}$ Institute for Health Economics and 
Clinical Epidemiology, University of Cologne, Cologne, Germany. ${ }^{3}$ Department of Non-Drug Interventions, Institute for Quality and Efficiency in Health Care, Cologne, Germany. ${ }^{4}$ Department of General, Abdominal, Vascular and Thoracic Surgery, Academic Hospital University Cologne, Cologne, Germany.

Received: 24 May 2016 Accepted: 12 October 2016

Published online: 18 October 2016

\section{References}

1. Kuhry E, Schwenk W, Gaupset R, Romild U, Bonjer J. Long-term results of laparoscopic colorectal cancer resection. Cochrane Database Syst Rev. 2008(5). doi:10.1002/14651858.CD003432.pub2

2. Schwenk W, Haase O, Neudecker JJ, Müller JM. Short term benefits for laparoscopic colorectal resection. Cochrane Database of Syst Rev. 2005;2: CD003145. doi:10.1002/14651858.CD003145.pub2.

3. Kössler-Ebs JB, Grummich K, Jensen K, Hüttner FJ, Müller-Stich B, Seiler CM, et al. Incisional hernia rates after laparoscopic or open abdominal surgery-a systematic review and meta-analysis. World J Surg. 2016;40(10):2319-30.

4. De Vivo A, Mancuso A, Giacobbe A, Priolo AM, De Dominici R, Maggio Savasta L. Wound length and corticosteroid administration as risk factors for surgical-site complications following cesarean section. Acta Obstet Gynecol Scand. 2010;89(3):355-9. doi:10.3109/00016340903568175.

5. Bucher $P$, Pugin F, Morel P. Single port access laparoscopic right hemicolectomy. Int J Colorectal Dis. 2008;23(10):1013-6. doi:10.1007/s00384-008-0519-8.

6. Remzi FH, Kirat HT, Kaouk JH, Geisler DP. Single-port laparoscopy in colorectal surgery. Colorectal Dis. 2008;10(8):823-6. doi:10.1111/j.1463-1318. 2008.01660.x.

7. Miller S, Causey MW, Damle A, Maykel J, Steele S. Single-incision laparoscopic colectomy: training the next generation. Surg Endosc. 2013;27(5):1784-90. doi:10.1007/s00464-012-2684-7.

8. Chow AGY, Purkayastha S, Zacharakis E, Paraskeva P. Single-Incision laparoscopic surgery for right hemicolectomy. Arch Surg. 2011;146(2):183-6. doi:10.1001/archsurg.2010.336.

9. Cianchi F, Qirici E, Trallori G, Mallardi B, Badii B, Perigli G. Single-incision laparoscopic colectomy: technical aspects and short-term results. Updates Surg. 2012;64:19-23. doi:10.1007/s13304-011-0112-5.

10. Maggiori L, Gaujoux S, Tribillon E, Bretagnol F, Panis Y. Single-incision laparoscopy for colorectal resection: a systematic review and meta-analysis of more than a thousand procedures. Colorectal Dis. 2012;14(10):e643-e54. doi:10.1111/j.1463-1318.2012.03105.x.

11. Zhou YM, Wu LP, Zhao YF, Xu DH, Bin L. Single-incision versus conventional laparoscopy for colorectal disease: a meta-analysis. Dig Dis Sci. 2012;57(8): 2103-12. doi:10.1007/s10620-012-2145-0.

12. Li P, Wang DR, Wang LH, Li YK, Chen J. Single-incision laparoscopic surgery vs. multiport laparoscopic surgery for colectomy: a meta-analysis of eleven recent studies. Hepatogastroenterology. 2012;59(117):1345-9. doi:10.5754/hge12156.

13. Yang TX, Chua TC. Single-incision laparoscopic colectomy versus conventional multiport laparoscopic colectomy: a meta-analysis of comparative studies. Int J Colorectal Dis. 2013;28(1):89-101. doi:10.1007/s00384-012-1537-0.

14. Markar SR, Wiggins T, Penna M, Paraskeva P. Single-Incision versus Conventional Multiport Laparoscopic Colorectal Surgery-Systematic Review and Pooled Analysis. J Gastrointest Surg. 2014. doi:10.1007/s11605-014-2654-6.

15. Podda M, Saba A, Porru F, Pisanu A. Systematic review with meta-analysis of studies comparing single-incision laparoscopic colectomy and multiport laparoscopic colectomy. Surg Endosc. 2016. [Epub ahead of print]

16. Brockhaus AC, Sauerland S, Saad S. Single-incision versus standard multiincision laparoscopic colectomy in patients with malignant or benign colonic disease (Protocol). Cochrane Database Syst Rev 2013 doi:10.1002/ 14651858.CD010717

17. Shea BJ, Grimshaw JM, Wells GA, Boers M, Andersson N, Hamel C, et al. Development of AMSTAR: a measurement tool to assess the methodological quality of systematic reviews. BMC Med Res Methodol. 2007;7:10. doi:10.1186/1471-2288-7-10.

18. Makino T, Milsom JW, Lee SW. Feasibility and safety of single-incision laparoscopic colectomy: a systematic review. Ann Surg. 2012;255(4):667-76. doi:10.1097/SLA.0b013e31823fbae7.

19. Poon JTC, Cheung CW, Fan JKM, Lo OSH, Law WL. Single-incision versus conventional laparoscopic colectomy for colonic neoplasm: a randomized, controlled trial. Surg Endosc. 2012;26(10):2729-34. doi:10.1007/s00464-012-2262-z.
20. Higgins JPT, Altman DG, Sterne JAC (editors). Chapter 8: Assessing risk of bias in included studies. In: Higgins JPT, Green S (editors). Cochrane Handbook for Systematic Reviews of Interventions Version 5.1.0 (updated March 2011). The Cochrane Collaboration; 2011. Available from www.cochrane-handbook.org.

21. Review Manager (RevMan) [Computer program]. Version 5.3. Copenhagen: The Nordic Cochrane Centre, The Cochrane Collaboration; 2014

22. Fung AK-Y, Aly EH. Systematic review of single-incision laparoscopic colonic surgery. Br J Surg. 2012;99(10):1353-64. doi:10.1002/bjs.8834.

23. Huscher CG, Mingoli A, Sgarzini G, Mereu A, Binda B, Brachini G, et al. Standard laparoscopic versus single-incision laparoscopic colectomy for cancer: early results of a randomized prospective study. Am J Surg. 2012; 204(1):115-20. doi:10.1016/j.amjsurg.2011.09.005.

24. Adair J, Gromski MA, Lim RB, Nagle D. Single-incision laparoscopic right colectomy: experience with 17 consecutive cases and comparison with multiport laparoscopic colectomy. Dis Colon Rectum. 2010;53(11):1549-54. doi:10.1007/DCR.0b013e3181e85875.

25. Champagne BJ, Lee EC, Leblanc F, Stein SL, Delaney CP. Single-incision vs straight laparoscopic segmental colectomy: a case-controlled study. Dis Colon Rectum. 2011;54(2):183-6. doi:10.1007/DCR.0b013e3181fd48af.

26. Chen WTL, Chang SC, Chiang HC, Lo WY, Jeng LB, Wu C, et al. Singleincision laparoscopic versus conventional laparoscopic right hemicolectomy: a comparison of short-term surgical results. Surg Endosc. 2011;25(6):1887-92. doi:10.1007/s00464-010-1481-4.

27. Chew MH, Change MH, Tan WS, Wong MT, Tang CL. Conventional laparoscopic versus single-incision laparoscopic right hemicolectomy: a case cohort comparison of short-term outcomes in 144 consecutive cases. Surg Endosc. 2013:27(2):471-7. doi:10.1007/s00464-012-2460-8.

28. Currò G, Cogliandolo A, Lazzara S, La Malfa G, Navarra G. Single-incision versus three-port conventional laparoscopic right hemicolectomy: is there any real need to go single? J Laparoendosci Adv Surg Tech A. 2012;22(7): 621-4. doi:10.1089/lap.2012.0120

29. Egi H, Hattori $M$, Hinoi T, Takakura $Y$, Kawaguchi $Y$, Shimomura $M$, et al. Single-port laparoscopic colectomy versus conventional laparoscopic colectomy for colon cancer: a comparison of surgical results. J Surg Oncol. 2012:10:61. doi:10.1186/1477-7819-10-61.

30. Fugii S, Watanabe K, Ota M, Watanabe J, Ichikawa Y, Yamagishi S, et al. Single-incision laparoscopic surgery using colon-lifting technique for colorectal cancer: a matched case-control comparison with standard multiport laparoscopic surgery in terms of short-term results and access instrument cost Surg Endosc. 2012;26(5):1403-11. doi:10.1007/s00464-011-2047-9.

31. Gandhi DP, Ragupathi M, Patel CB, Ramos-Valadez DI, Pickron TB, Haas EM. Single-incision versus hand-assisted laparoscopic colectomy: a case-matched series. J Gastrointest Surg. 2010;14(12):1875-80. doi:10.1007/s11605-010-1355-z.

32. Gaujoux S, Maggiori L, Bretagnol F, Ferron M, Panis Y. Safety, feasibility, and short-term outcomes of single port access colorectal surgery: a single institutional case-matched study. J Gastrointest Surg. 2012;16(3):629-34. doi:10.1007/s11605-011-1780-7.

33. Keshava A, Young CJ, Richardson GL, De-Loyde K. A historical comparison of single incision and conventionalmultiport laparoscopic right hemicolectomy. Colorectal Dis. 2013;15(10):e618-22. doi:10.1111/codi.12380.

34. Kim SJ, Ryu GO, Choi BJ, Kim JG, Lee KJ, Lee SC, et al. The short-term outcome of conventional and single-port laparoscopic surgery for colorectal cancer. Ann Surg. 2011;254(6):933-40. doi:10.1097/SLA.0b013e318237826b.

35. Kwag SJ, Kim JG, Oh ST, Kang WK. Single incision vs conventional laparoscopic anterior resection for sigmoid colon cancer: a case-matched study. Am J Surg. 2013;206(3):320-25. doi:10.1016/j.amjsurg.2012.11.007.

36. Lai CW, Edwards TJ, Clements DM, Coleman MG. Single port laparoscopic right colonic resection using a 'vessel-first' approach. Colorectal Dis. 2012; 14(9):1138-44. doi:10.1111/j.1463-1318.2011.02898.x.

37. Lee SW, Milsom JW, Nash GM. Single-incision versus multiport laparoscopic right and hand-assisted left colectomy: a case-matched comparison. Dis Colon Rectum. 2011;54(11):1355-61. doi:10.1097/DCR Ob013e31822c8d41.

38. Lu CC, Lin SE, Chung KC, Rau KM. Comparison of clinical outcome of single-incision laparoscopic surgery using a simplified access system with conventional laparoscopic surgery for malignant colorectal disease. Colorectal Dis. 2012:14(4):e171-6. doi:10.1111/j.1463-1318.2011.02825.x.

39. McNally ME, Moore BT, Brown KM. Single-incision laparoscopic colectomy formalignant disease. Surg Endosc. 2011;25(11):3559-65. doi:10.1007/s00464011-1758-2. 
40. Osborne AJ, Lim J, Gash KJ, Chaudhury B, Dixon AR. Comparison of singleincision laparoscopic high anterior resection with standard laparoscopic high anterior resection. Colorectal Dis. 2013;15(3):329-33. doi:10.1111/j.14631318.2012.03178.x

41. Papaconstantinou HT, Thomas JS. Single-incision laparoscopic colectomy for cancer: assessment of oncologic resection and short-term outcomes in a case-matched comparison with standard laparoscopy. Surgery. 2011;150(4): 820-7. doi:10.1016/j.surg.2011.07.060.

42. Pedraza R, Aminian A, Nieto J, Faraj C, Pickron TB, Haas EM. Single-incision laparoscopic colectomy for cancer: short-term outcomes and comparative analysis. Minim Invasive Surg. 2013;2013:283438. doi:10.1155/2013/283438.

43. Ramos-Valadez DI, Ragupathi M, Nieto J, Patel CB, Miller S, Pickron TB, et al. Single-incision versus conventional laparoscopic sigmoid colectomy: a case-matched series. Surg Endosc. 2012;26(1):96-102. doi:10.1007/ s00464-011-1833-8.

44. Vasilakis V, Clark CE, Liasis L, Papaconstantinou HT. Noncosmetic benefits of single-incision laparoscopic sigmoid colectomy for diverticular disease: a case-matched comparison with multiport laparoscopic technique. J Surg Res. 2013;180(2):201-7. doi:10.1016/j.jss.2012.04.063.

45. Velthius S, van den Boezem PB, Lips DJ, Prins HA, Cuesta MA, Sietses C. Comparison of short-term surgical outcomes after singleincision laparoscopic versus multiport laparoscopic right colectomy: a two-center prospective case controlled study of 100 patients. Dig Surg. 2012;29:477-83.

46. Waters JA, Guzman MJ, Fajardo AD, Selzer DJ, Wiebke EA, Robb BW, et al. Single-port laparoscopic right hemicolectomy: a safe alternative to conventional laparoscopy. Dis Colon Rectum. 2010;53(11):1467-72. doi:10.1007/DCR. Ob013e3181f23ca0.

47. Wolthius AM, Pennickx F, Fieuws S, D'Hoore A. Outcomes for case-matched single-port colectomy are comparable with conventional laparoscopic colectomy. Colorectal Dis. 2012;14(5):634-41. doi:10.1111/j.1463-1318.2011.02721.x.

48. Yun JA, Yun SH, Park YA, Cho YB, Kim HC, Lee WY, et al. Single-incision laparoscopic right colectomy compared with conventional laparoscopy for malignancy: assessment of perioperative and short-term oncologic outcomes. Surg Endosc. 2013;27(6):2122-30. doi:10.1007/s00464-012-2722-5.

49. Katsuno G, Fukunaga M, Lee Y. Single-incision versus conventional laparoscopic colectomy: a case-matched series of 90 cases. Surg Endosc. 2012;26:S249-430

50. Lim SW, Kim HR, Kim YJ. Single incision laparoscopic colectomy for colorectal cancer: comparison with conventional laparoscopic colectomy. Ann Surg Treat Res. 2014;87(3):131-8. doi:10.4174/astr.2014.87.3.131.

51. Khayat A, Maggiori L, Vicaut E, Ferron M, Panis Y. Does single port improve results of laparoscopic colorectal surgery? A propensity score adjustment analysis. Surg Endosc. 2015;29(11):3216-23. doi:10.1007/s00464-015-4063-7.

52. Champagne BJ, Papaconstantinou HT, Parmar SS, Nagle DA, Young-Fadok TM, Lee EC, et al. Single-incision versus standard multiport laparoscopic colectomy: a multicenter, case-controlled comparison. Ann Surg. 2012; 255(1):66-9. doi:10.1097/SLA.0b013e3182378442.

53. Kanakala V, Borowski DW, Agarwal AK, Tabaqchali MA, Gard DK, Gill TS. Comparative study of safety and outcomes of single-port access versus conventional laparoscopic colorectal surgery. Tech Coloproctol. 2012;16(6): 423-8. doi:10.1007/s10151-012-0839-0.

54. Mynster T, Wille-Jorgensen P. Case-mix study of single incision laparoscopic surgery (SILS) vs. conventional laparoscopic surgery in colonic cancer resections. Pol Przegl Chir. 2013;85(3):123-8. doi:10.2478/pjs-2013-0021.

55. Papaconstantinou HT, Sharp N, Thomas JS. Single-incision laparoscopic right colectomy: a case-matched comparison with standard laparoscopic and hand-assisted laparoscopic techniques. J Am Coll Surg. 2011;213(1):72-80. doi:10.1016/j.jamcollsurg.2011.02.010.

56. Rijcken E, Mennigen R, Argyris I, Senninger N, Bruewer M. Single-incision laparoscopic surgery for ileocolic resection in Crohn's disease. Dis Colon Rectum. 2012;55(2):140-6. doi:10.1097/DCR.0b013e31823d0e0d.

57. Rosati CM, Boni L, Dionigi G, Cassinotti E, Giavarini L, David G, et al. Single port versus standard laparoscopic right colectomies: results of a casecontrol retrospective study on one hundred patients. Int J Surg. 2013;11 Suppl 1:S50-3. doi:10.1016/S1743-9191(13)60016-3.

58. Takemasa I, Uemura M, Nishimura J, Mizushima T, Yamamoto H, Ikeda M, et al. Feasibility of single-site laparoscopic colectomy with complete mesocolic excision for colon cancer: a prospective case-control comparison. Surg Endosc. 2014;28(4):1110-8. doi:10.1007/s00464-013-3284-x.

59. Katsuno G FM, Tsumura $\mathrm{H}$ et al. Single incision laparoscopic colectomy (SILC) for colorectal cancer: a case matched series of 100 cases. In: 2011
Scientific Session of the Society of American Gastrointestinal and Endoscopic Surgeons, SanAntonio, TX. 2011

60. Lim SW, Huh JW, Kim YJ, Kim HR. Prospective Randomized Trial Comparing Transumblical Incision and Left Lower Transverse Incision for Specimen Delivery in Laparoscopic Surgery of Colorectal Cancer. Society of American Gastrointestinal and Endoscopic Surgeons (SAGES), society meeting. 2011.

61. Lee SH, Kang BM, Park SJ, Lee KY, editors. The single port laparoscopic surgery can be performed safely and appropriately in colon cancer. The analysis of the pilot prospective randomized trials [abstract]. Colorectal Disease; 2011.

62. Chow M, Day W, Kwok S, Lau Y. Comparison of single-incision right hemicolectomy and conventional multiport laparoscopic right hemicolectomy: A randomized trial [conference abstract, ASCRS 2014, P374]. Diseases of the Colon and Rectum. 2014; e342.

63. Sheligin Y, Achkasov S, Zapolskiy A. Results of specimen quality evaluation after laparoscopic right colectomies, performed by multiport and SILS approaches: Prospective randomised trial [conference abstract, ESCP 2014 LTP90]. Colorectal Disease. 2014;16(Suppl 3):21-36.

64. Shelygin Y, Achkasov S, Sushkov O, Zapolskiy A. Results of laparoscopic right colectomies, performed by multi- and single-port approaches for cancer. Prospective randomised trial [conference abstract, ESCP 2015, OP33]. Colorectal Disease. 2015;17(15)

65. Wang Y, Liu R, Zhang Z, Xue Q, Yan J, Yu J, et al. A safety study of transumbilical single incision versus conventional laparoscopic surgery for colorectal cancer: Study protocol for a randomized controlled trial. Trials. 2015:16(1):539.

66. Bonferroni CE. Teoria statistica delle classi e calcolo delle probabilità. Pubblicazioni del R Istituto Superiore di Scienze Economiche e Commerciali di Firenze. Libreria internazionale Seeber; 1936.

67. Victor A, Elsäßer A, Hommel G, Blettner M. Judging a plethora of $p$-Values how to contend with the problem of multiple testing part 10 of a series on evaluation of scientific publications. Dtsch Arztebl Int. 2010;107(4):50-6. doi: 10.3238/arztebl.2009.0050

68. Kelley AM. Does the clinically significant difference in visual analog scale pain scores vary with gender, age, or cause of pain? Acad Emerg Med. 1998;5(11):1086-90.

69. Odgaard-Jensen J, Vist GE, Timmer A, Kunz R, Akl EA, Schünemann H, et al. Randomisation to protect against selection bias in healthcare trials (Review). Cochrane Database Syst Rev. 2011(4). doi:10.1002/14651858.MR000012.pub3

70. Hemkens LG, Contopoulos-loannidis DG, loannidis JPA. Agreement of treatment effects for mortality from routinely collected data and subsequent randomized trials: meta-epidemiological survey. BMJ. 2016;352: i493. doi:10.1136/bmj.i493.

71. Jørgensen L, Rosenberg J, Al-Tayar H, Assaadzedh S, Helgstrand F, Bisgaard T. Randomized clinical trial of single- versus multi-incision laparoscopic cholecystectomy. Br J Surg. 2014;101(4):347-55. doi:10.1002/bjs.9393.

72. Garg P, Thakur JD, Garg M, Menen GR. Single-incision laparoscopic cholecystectomy vs. Conventional laparoscopic cholecystectomy- a metaanalysis of randomized controlled trials. J Gastrointest Surg. 2012;16(8):1618-28. doi:10.1007/s11605-012-1906-6.

\section{Submit your next manuscript to BioMed Central and we will help you at every step:}

- We accept pre-submission inquiries

- Our selector tool helps you to find the most relevant journal

- We provide round the clock customer support

- Convenient online submission

- Thorough peer review

- Inclusion in PubMed and all major indexing services

- Maximum visibility for your research

Submit your manuscript at www.biomedcentral.com/submit 